\title{
BUSCANDO A COMPREENSÃO DO ENFRENTAMENTO DA AIDS NO BRASIL
}

Lúcia Yasuko Izumi Nichiata*

Hisako Shima*

Renata Ferreira Takahashi *

O trabalho dimensiona e analisa a tendência da evolução da AIDS no Brasil e busca compreender o modo como se deu o seu enfrentamento no país considerando o contexto histórico e social em que a infecção emerge e dissemina.

UNITERMOS: AIDS magnitude e evolução, enfrentamento da epidemia, programa de prevenção e controle

\section{A REAL DIMENSÃO DA EPIDEMIA DE AIDS NO BRASIL}

É possível prever um quadro bastante assustador ao se debruçar sobre as estatísticas relativas à Síndrome de Imunodeficiência Adquirida (AIDS) disponíveis no país e constatar a velocidade de sua disseminação no nosso meio.

Desde o início da epidemia, o Brasil vem figurando entre os principais países do mundo que apresentam o maior número de casos de AIDS, ocupando, na América Latina, o primeiro lugar, com uma estimativa de 750.000 infectados $^{8}$. Infelizmente, ao se tratar de estatísticas negativas, conseguiu-se, com freqüência, um lugar de destaque no cenário mundial.

De junho de 1980 até abril de 1994 foram notificados no país 51.942 casos, sendo que os dados de incidência demonstram uma tendência anual ascendente. Tomando-se o período de 1980 a 1986, a taxa foi de 1,4/100 mil habitantes, enquanto que em 1990, essa cifra atingiu 4,9/100 mil habitantes, chegando em 1993/94 a 7,1/100 mil habitantes ${ }^{4}$.

*Docente do Departamento de Enfermagem em Saúde Coletiva da Escola de Enfermagem da Universidade de São Paulo 
O Estado de São Paulo vem ocupando o primeiro lugar em número de casos, respondendo hoje por cerca de $32,6 \%$ do total nacional ${ }^{4}$. Quanto à distribuição geográfica dos casos, encontra-se concentração em algumas localidades como o Município de São Paulo e cidades como Santos, São Vicente, e São José do Rio Preto, locais esses com características turísticas, portuárias ou que fazem parte da rota de tráfico de drogas ${ }^{16}$.

No Município de São Paulo a doença já constitui a principal causa de morte entre as doenças transmissíveis na faixa etária acima dos 15 anos, ultrapassando a tuberculose ${ }^{23}$.

Similarmente a outros países, a infecção foi identificada inicialmente entre os homossexuais masculinos, mas, no decorrer de quase 15 anos de epidemia, observou-se uma clara alteração no perfil de contaminação pelo Vírus da Imunodeficiência Humana (HIV).

No período de 1980 a 1991, segundo a categoria de transmissão, verificou-se que $48 \%$ de todos os casos se referiam a homo ou bissexuais masculinos, mas a sua proporção decresceu de 63,2\%, no período de 1980 a 1986, para 42,1\% de 1991 a $1992^{6}$. A partir de 1987, observou-se um crescimento gradativo do percentual de infectados pelo HLV em usuários de drogas endovenosas e aumento progressivo e expressivo do número de mulheres infectadas, principalmente como conseqüência do relacionamento destas com parceiros bissexuais ou usuários de drogas, o que tem refletido maior número de casos em crianças menores de um ano, em decorrência da transmissão vertical ${ }^{4,6}$.

No início da epidemia, a transfusão sangüínea era uma das principais formas de transmissão do vírus hoje em decorrência da instituição do Programa de Controle Sangue e Hemoderivados, a proporção de contaminados por transfusão sangüínea é menor, mas de qualquer forma, o número total de casos continua sendo significativo.

Mais de uma década após a descoberta da AIDS em nosso meio, não é mais possível considerá-la circunscrita a determinados grupos de risco.

Essa situação é ainda mais preocupante se for lembrado que esses dados se referem apenas aos casos inseridos no sistema de notificação compulsória que, além de subestimar o real número de casos, dizem respeito somente àqueles que já atingiram uma etapa mais avançada do processo infeccioso, passando a apresentar sinais e sintomas clínicos evidentes que permitiram a confirmação da doença. Da forma como se encontra normatizada a notificação compulsória - não obrigatoriedade de comunicar os portadores assintomáticos -, é difícil precisar o que representa este contingente. Aceitando-se que para cada doente de AIDS existem de 50 a 100 portadores assintomáticos ${ }^{14}$, é realmente assustador buscar dimensionar este número, o qual GUIMARÃES et $\mathrm{al}^{12}$ se referem como "exército epidemiológico de reserva de AIDS"**

${ }^{\star \star}$ Carmem Dora GUIMARAES, et al, Segundo relatório de pesquisa: o impacto social da AIDS, p. 12 
É patente, portanto, que a dimensão real da epidemia é, na realidade, muito maior do que a revelada pelos dados estatísticos oficiais.

\section{CONTEXTUALIZANDO O ENFRENTAMENTO DA AIDS NO BRASIL}

Para entender o aparecimento e a difusão da AIDS, bem como a sua forma de enfrentamento no Brasil, é necessário circunstanciara especificidade do momento histórico que vivia o país na década de 80 , buscando se extrair da história elementos que possam subsidiar esta compreensão.

Para tanto, reportar-se-á a partir do envolvimento do país no projeto mundial de internacionalização da economia. O Brasil, assim como os demais países do Terceiro Mundo, logrado pela facilidade de acesso aos créditos internacionais e pela possibilidade de participação no mercado internacional, assume, basicamente após 1964, a abertura da economia ao exterior e a acumulação do capital interno como estratégias privilegiadas para alcançar o esperado desenvolvimento econômico ${ }^{25}$.

Resultou deste imenso entrelaçamento da economia mundial, maior integração espacial e maior mobilidade e contato social da população ${ }^{20}$, com reflexos no cenário epidemiológico; já que o aumento da mobilidade populacional acelera o risco de introdução de diversas doenças transmissíveis a partir de hospedeiros, vetores ou veículos contaminados ${ }^{5}$.

Assim, é possível, segundo SABROSA et $\mathrm{al}^{19}$, que a disseminação do vírus HIV antes isolado em nichos ecológicos restritos no continente africano - possa ser entendida como decorrente das profundas alterações que acompanharam o desenvolver da sociedade contemporânea.

Se antes de 1964, a industrialização no Brasil era basicamente voltada para o mercado interno, a partir da abertura de possibilidades de participação no circuito internacional do capital ocorre um incentivo à expansão de importantes setores da indústria, principalmente daqueles ligados à exportação. Isto possibilitou que o país conhecesse um período de crescimento econômico, cujo ápice ocorreu entre 1968 a 1971, conhecido como "milagre econômico"25.

Entretanto, já em 1973 eram evidentes os sinais de que o "milagre" encerrava o ciclo de crescimento econômico. Segundo SINGER ${ }^{25}$, a expansão das indústrias de exportação acabou por acentuar o duplo vínculo de dependência com os países centrais. O país ficou à mercê dos mercados internacionais por um lado, e por outro, tornou-se dependente em grau crescente do fornecimento de equipamentos e tecnologia. Além disso, ao priorizar o crescimento "para fora", negligenciando a expansão de atividades ligadas ao mercado interno, acabou por condicionar posteriormente um quadro de "desabastecimento" geral, que 
levou a economia brasileira à falta de matérias-primas, bens de consumo assim como mãode-obra.

A partir daí, iniciou-se um período infindável de crises de todas as naturezas, com total desaceleração do crescimento da economia, crescente aumento do endividamento externo, intensa recessão e arrocho salarial, concentração cada vez maior da renda e degradação da qualidade de vida de extensa camada da população brasileira ${ }^{2}$.

Diante desta crise no início da década de 80 , o setor saúde se defronta por um lado, com o aumento da pressão de demanda por serviços, devido à crescente deterioração das condições de saúde de grande parte da população, enquanto por outro, vê diminuída a sua capacidade financeira. $O$ decrescente financiamento que se seguiu no setor acabou por estabelecer uma conjuntura de deterioração tanto dos recursos materiais e de equipamentos, quanto dos recursos humanos, dando início a um processo de desmantelamento do aparelho estatal de saúde pública ${ }^{11,15}$.

Além disso, era evidente a dicotomia do Sistema de Saúde, dividido por um lado, em ações de saúde pública desempenhadas pelo setor público e, por outro, nas ações de cuidados médicos individuais marcadamente de caráter curativo, em poder do setor privado, através do sistema previdenciário de assistência médica; isso implicou em profundas desigualdades no acesso dos usuários aos serviços de assistência à saúde.

A crise econômica, suas manifestações sobre as condições de vida da população e um sistema de saúde excludente que se mostrou incapaz de influir decisivamente sobre o quadro de saúde do país, fizeram com que o Estado reconhecesse também a existência de uma crise no setor saúde ${ }^{17}$. Neste contexto, acirraram-se as discussões em torno da necessária Reforma Sanitária que subsidiaram as propostas de mudança do sistema vigente, tanto relativas à redefinição das política de saúde como condição necessária para a consolidação democrática, bem como aquelas relacionadas à própria problematização e conceituação de saúde e doença ${ }^{17}$.

A mobilização da sociedade, representada pelos movimentos populares, igreja, imprensa, profissionais de saúde, políticos etc., em torno dessas questões, resultou num "Movimento pela Reforma" de âmbito nacional, fazendo com que a saúde se constituísse em direito de fato, legitimado, a partir da promulgação da nova Constituição Nacional, em 1988, definindo-se como princípio da reestruturação do setor, o Sistema Único de Saúde ${ }^{7}$.

Neste período de transição, momento em que começavam a ser esboçadas as propostas de reforma de um sistema de saúde praticamente falido, emergia a AIDS, o que talvez explique, em parte, a ausência de um pronto enfrentamento por parte do Estado e da sociedade civil, permitindo a franca disseminação da infecção no país.

Ao mesmo tempo, é inegável que a forma como emergiu a AIDS - inicialmente detectada em grupos de homossexuais masculinos e a seguir entre usuários de drogas endovenosas - influiu profundamente na resposta da sociedade que se manteve por muito 
tempo alienada à doença, acreditando que ela se restringiria a apenas alguns grupos de risco. A Associação Brasileira Interdisciplinar de AIDS (ABIA) ${ }^{1}$ comenta ser esta uma curiosa postura: "espera primeiro que o problema se tome tão grande, que fique tão insolúvel quanto outros decorrentes de outras endemias e epidemias que atingem o povo

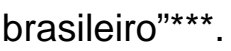

Esta visualização da AIDS como restrita a determinados "grupos de risco" imprimiu um forte caráter estigmatizante, pois repassou a idéia de que ela afetava somente pessoas que apresentavam comportamentos altamente condenados pela sociedade. Determinados meios de comunicação de massa, somados a atitudes indesejáveis de alguns profissionais de saúde, tiveram papel fundamental na construção social e cultural da AIDS, fomentando o medo e o preconceito através da reprodução e divulgação de informações distorcidas e equivocadas com relação a doença, fazendo com que até hoje os portadores do vírus HIV sejam alvo de condenação, preconceitos, medo e discriminação.

SOUZA $^{26}$ alerta para a maneira direta como a doença se encontra relacionada à questão do sexo e da morte. Explica que ao relacionar a doença à questão da sexualidade, indubitavelmente leva à repressão sexual por um lado e, por outro, a questões da moral, que por sua vez resulta em dois subprodutos extremamente danosos a qualquer sociedade: a criminalização de um fenômeno de saúde e a marginalização de pessoas afetadas por uma doença. Acrescenta que, além disso, a vinculação da doença com a morte é um complicador importante na abordagem da AIDS, porque provoca de imediato o pânico entre as pessoas. Essas estratégias, além de não contemplarem a verdadeira compreensão sobre as raízes deste fenômeno, acabam, como afirmam SABROSA et $\mathrm{al}^{19}$, por disseminar o preconceito e a negação do problema e, portanto, são impeditivas de ação que ultrapassem o nível individual.

Este entendimento distorcido a respeito da doença tem contribuído para a falta de solidariedade e reforçado a alienação da sociedade geral, constituindo-se, sobretudo, num dos motivos que retardou a adoção de ações coletivas de intervenção.

$A A B I A^{1}$ - denuncia que, inicialmente, o próprio Ministério da Saúde, por considerar a AIDS como um problema localizado e restrito aos chamados grupos de risco, não a visualizou como um problema que merecesse investimentos para a adoção de um programa nacional integrado de combate à epidemia; argumentava que outros problemas de maior magnitude eram prioritários naquele momento. A resposta governamental formal surgiu somente quatro anos após o primeiro caso, ou seja, somente em 1985, quando é criado o Programa Nacional de Controle da AIDS pelo Ministério da Saúde.

${ }^{\star \star * A B I A, ~ A I D S ~ n o ~ B r a s i l: ~ f a c e ~ v i s i ́ v e l ~ e ~ f a c e ~ o c u l t a, ~ A c ̧ a ̃ o ~ A n t i-A i d s, ~ n . ~ 11, ~ p . ~} 10$ 
A demora na tomada de posição, por parte das autoridades sanitárias, é verificada também no caso dos bancos de sangue. Segundo SILVA ${ }^{24}$, somente em 1985 é que se tentou-se implementar o controle do sangue em hemocentros, sendo que a obrigatoriedade legal da realização do teste anti-HIV nestes locais só ocorreu em 1988, oito anos depois da descoberta do vírus. Relutava-se em tornar obrigatória a realização do exame, utilizando os mesmos argumentos que vinham sendo apontados anteriormente: que a doença não era prioritária, em face de outros problemas de saúde e que esta medida demandaria grande soma de recursos ${ }^{2}$.

O descaso que se verificou em relação às questões do controle do sangue no início da epidemia, resultou na expansão da AIDS transfusional. Segundo SOUZA ${ }^{27}$, neste período, 95\% dos hemofílicos foram infectados através do sangue e seus derivados contaminados.

Outra questão que dificulta consideravelmente o enfrentamento da AIDS no Brasil diz respeito ao consumo e ao tráfico de drogas, que extrapolam as dimensões do controle específico do setor saúde. Hoje, o nosso país como integrante da rota obrigatória da distribuição mundial de cocaína, possui pelo menos 100 mil traficantes e aponta-se que o consumo de drogas entre os jovens cresce $25 \%$ a cada $a 0^{3}$. Sendo o comércio e o tráfico de drogas, fontes alternativas de subsistência para uma parcela expressiva da população, é fácil imaginar a gama de interesses que estão envolvidos nos diversos segmentos da sociedade, inviabilizando o seu efetivo controle.

Acresce-se a isso, a dificuldade de recuperação dos toxicômanos conforme se verifica nas experiências de assistência que não tem sido respostas satisfatórias ${ }^{16}$.

No caso do Estado de São Paulo, foi essencial a participação da sociedade civil no que diz respeito ao desencadeamento das atividades iniciais para o enfrentamento da epidemia. Como ressalta GUERRA ${ }^{13}$, a mobilização de alguns grupos da população, como os homossexuais masculinos, teve papel fundamental ao pressionar as autoridades sanitárias estaduais para que se acolhesse a AIDS como questão relevante, antevendo a dimensão que a doença viria a assumir, como de fato ocorreu.

Assim, já em 1983, a Secretaria de Estado da Saúde de São Paulo começou a implementar as primeiras atividades de controle, antecipando-se à configuração do Programa Nacional do Ministério da Saúde ${ }^{13}$.

O Programa de Prevenção e Controle da AIDS no nível estadual previa, entre outras medidas, a descentralização do atendimento ambulatorial, a ampliação do número de leitos hospitalares e a realização de campanhas educativas para prevenção da infecção ${ }^{22}$.

Dentre as iniciativas implementadas pelo Estado, merece destaque a criação do Centro de Referência e Treinamento em AIDS (CRTA) em 1988, que além de realizar atividades assistenciais (principalmente através do hospital-dia e ambulatório), e de vigilância epidemiológica, tem sido responsável pela capacitação da maioria dos trabalhadores da rede de saúde de todo o Estado para a assistência à AIDS ${ }^{13}$.

A Secretaria Municipal por sua vez, tem procurado capacitar os profissionais de 
saúde para a assistência aos pacientes com AIDS e aos anti-HIV soropositivos, além de buscar viabilizar a ampliação do número de leitos hospitalares destinados aos doentes de AIDS. No campo da prevenção e educação foram criados os Centros de Orientação e Aconselhamento Sorológico em DST/AIDS, com os objetivos de dispor a avaliação sorológica anônima e confidencial, fornecer preservativos, bem como de dar orientação e aconselhamento sobre AIDS à população em geral e a grupos específicos (como prostitutas e usuários de drogas) ${ }^{22}$.

Não se pode esquecer que neste enfrentamento, a sociedade civil não se manteve alheia. Grupos organizados da população foram se engajando na luta e hoje existe uma Rede Brasileira de Solidariedade que congrega as organizações não governamentais (ONGs) envolvidas no combate à epidemia concebendo "a solidariedade como uma prática de luta política pela cidadania"10.

Recentemente, um dos principais jornais do país referia que "a epidemia está provocando o maior 'boom' de movimentos civis já registrados no século. Só no Brasil, mais de 200 entidades nasceram em torno da AIDS e hoje militam em várias frentes" ${ }^{\star \star \star \star}$.

\section{CONSIDERAÇÕES FINAIS}

Apesar das medidas governamentais e o envolvimento da sociedade civil no enfrentamento da AIDS, os diversos anos de epidemia têm demonstrado a incapacidade do Estado em controlar a disseminação da doença que cresce em escala progressiva. Se hoje, as instituições de saúde não conseguem mais dar conta sequer da demanda de doentes em fase avançada ou terminal, é fácil prever a situação caótica que instalar-se-á no futuro, caso medidas realmente efetivas para o controle da exposição e da infecção pelo HIV não sejam implementadas, em caráter de urgência.

Segundo analisa GUERRA ${ }^{13}$, o Programa de Controle da AIDS proposto pelo Estado não se efetivou por ter tido um caráter autoritário e verticalizado, deixando de envolver na sua elaboração os profissionais responsáveis pelo atendimento direto à população infectada pelo vírus. Além disso, argumenta a autora que "(...) a não enunciação clara de direitos e deveres, isto é, a cumplicidade entre esse Estado e uma sociedade civil essencialmente desigual, no que diz respeito à cidadania, favoreceu o não obedecimento daquelas regras que disciplinam o viver coletivo e privilegiam o interesse privado em detrimento do público. O direito e o dever foram acolhidos de modo a satisfazer um Estado que não é de

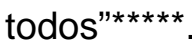

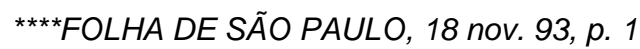

*****Maria Aparecida GUERRA, Política de controle da AIDS da Secretaria de Estado da Saúde de São Paulo, no período 1983-1992, p. 20 
Concordamos com a $\mathrm{ABIA}^{1}$ quando pondera que "o enfrentamento dos complexos desafios colocados na luta contra a AIDS só se pode dar na ação coletiva (...)"******. Ações essas que devem ser destituídas de atitudes preconceituosas, estar articuladas com diversos níveis da sociedade e ter como propósito a discussão do processo de produção da saúde e da doença da população brasileira.

Apesar de se prever um futuro bastante preocupante em relação ao quadro da AIDS no Brasil, é preciso reconhecer que este fenômeno trouxe alguns benefícios no que se refere à área da saúde. Fez repensar a qualidade dos nossos serviços de saúde, ressuscitou a importância das normas internacionais de biossegurança, trouxe à tona a discussão ético-legal na assistência à saúde, mostrou a força e o poder dos meios de comunicação de massa e, sobretudo, possibilitou a forte mobilização da sociedade civil em torno de uma questão de saúde.

Por outro lado, a AIDS privilegia visualizar a intrincada articulação das dimensões biológicas, cultural, econômica e política de uma dada enfermidade, aclarando as limitações de se analisá-la de um modo reducionista através de um enfoque fortemente embasado no biológico. Explicitou também a essencialidade de se considerar as representações construídas a respeito dos fenômenos sociais.

Não se pretende com isso, ter esgotado as questões que cercam esta epidemia do final do século. Buscamos apenas pontuar algumas reflexões acerca deste fenômeno no sentido de que muito da história social da AIDS necessita ainda ser desvendada. E, só a partir daí, poder-se-á adotar ações efetivas de intervenção coletiva que permitam o controle da sua disseminação evitando-se que concretize a previsão assustadora de PIERRET \& HERZLICH ${ }^{18}$ de que a epidemia passará a atingir "mais particularmente (...) os habitantes dos continentes mais deserdados e, nos países industrializados, os indivíduos menos aptos

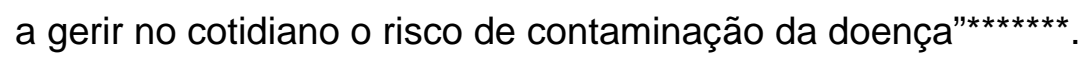

\section{UNDERSTANDING AIDS IN BRAZIL}

The authors discuss and analyze the magnitude and the evolution of the AIDS epidemic in Brazil. They evaluate how the infection has being approached in this country, taking into account the historical and social context in which It appeared and disseminated.

UNITERMS: AIDS, magnitude and evolution, approach to the epidemic, prevention and control program

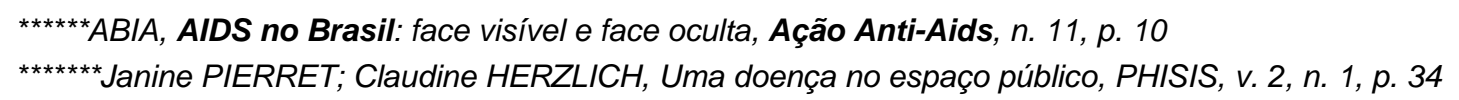




\section{BUSCANDO LA COMPRENSION DEL MODO DE ENFRENTAMIENTO DE LA “SIDA” EN BRASIL}

El trabajo dimensiona y analiza la tendencia de la evolución de la "SIDA" en Brasil y busca comprender el modo en que se dio y su abordaje en el país, considerando el contexto histórico y social en que la infección emerge y se disemina.

UNITERMOS:SIDA, magnitud y evolución, abordaje de la epidemia, programa de prevención y control

\section{REFERÊNCIAS BIBLIOGRÁFICAS}

01. ABIA. AIDS no Brasil: face visível e face oculta. Ação anti-aids, n. 11, p. 9-10, 1990.

02. ABRASCO/CEBES. Saúde é qualidade de vida. ABRASCO/CEBES: Rio de Janeiro/ Brasília, 1992, p. 8.

03. ARBEX Jr., J. Narcotráfico: um jogo de poder nas Américas. São Paulo: Moderna, 1993.

04. BRASIL. Ministério da Saúde. Bol. Epidemiol. AIDS, Brasília, v. 7

05. CARVALHEIRO, J.R. Processo migratório e disseminação de doenças. In: TEXTOS DE APOIO: Ciências Sociais, 2. 2. ed. Rio de Janeiro: ABRASCO, 1991. p. 29-55.

06. CASTILHO, E. C.; CHEQUER, P.; STRUCHINER, C. J. AIDS no Brasil. In: ...CENEPI Informe Epidemiológico, n. 3, ago. 1992.

07. CORDEIRO, H. Sistema Único de Saúde. Rio de Janeiro: Ayuri Editorial, 1991. p. 11938.

08. EL SIDA en América Latina y el Caribe: situación actual. Bol.Epidemiol. v. 13, n. 1, p. 17, 1992.

09. FOLHA DE SÃO PAULO. São Paulo, 28 nov. 1993. cad. 4, p. 1.

10. GALVÃO, J. AIDS: a doença e os doentes. Comunicações do Iser, n. 17, p. 42-7, dez. 1985.

11. GONÇALVES, R. B. M. A saúde no Brasil: algumas características do processo histórico nos anos 80. São Paulo em Perspectiva, v. 5, n. 1, p. 99-106,jan./ mar. 1991.

12. GUIMARAES, C. D., DANIEL, H., GALVÃO, J. Segundo relatório de pesquisa: o impacto social da AIDS no Brasil. Rio de Janeiro: ABIA, 1988. (mimeografado). 
13. GUERRA, M. A. T. Política de controle da AIDS da Secretaria de Estado da Saúde de São Paulo, no período 1983-1992: a história contada por seus agentes. São Paulo, p. 280. Dissertação (Mestrado) - Faculdade de Medicina, Universidade de São Paulo, 1993.

14. LEVY, G. C., BALDY, J. L. da S. AIDS/SIDA: síndrome da imunodeficiência adquirida. In: AMATO NETO, V., BALDY, J.L. da S. Doenças transmissíveis. 3. ed.. São Paulo: Sarvier, 1989. p. 146.

15. LUZ, M. T. Notas sobre as políticas de saúde no Brasil de transição democrática - anos 80. Saúde \& Debate, n. 32, p. 27-32, jun. 1991.

16. MESQUITA, F.C. AIDS e drogas injetáveis. In: SAÚDE \& LOUCURA. São Paulo, HUCITEC, 1991. p. 47-53, n. 3.

17. OLIVEIRA, J. A. DE A.; TEIXEIRA, S. M. F. (Im) previdência social: 60 anos de história da previdência no Brasil. Petrópolis: Vozes, 1986.

18. PIERRET, J.; HERZLICH, C. Uma doença no espaço público: a AIDS em seis jornais franceses. PHISYS, v. 2, n. 1, p. 7-35, 1993.

19. SABROSA, P. C.; TOLEDO, L. M.; OSANAI, C.H. A organização do espaço e os processos endêmico-epidêmicos. In: LEAL, M. do C. et al. Saúde, ambiente e desenvolvimento: processos e conseqüências sobre as condições de vida. São Paulo: HUCITEC, 1992 a. v. 2, p. 5 7-77.

20. SABROSA, P. C.; LEAL, M. C. Saúde, ambiente e desenvolvimento: alguns conceitos fundamentais. In: LEAL, M. do $C$. et al. Saúde, ambiente e desenvolvimento: processos e conseqüências sobre as condições de vida. São Pauto, Hucitec, 1992 b. v.1, p. 45-93.

21. SANTOS, L. G. dos. A questão do sangue. Saúde \& Debate, n. 27, p. 36-7, 1989.

22. SÃO PAULO (Cidade). Prefeitura do Município de São Paulo. Secretaria Municipal da Saúde. Programa de Prevenção e Controle das DSTIAIDS. Relatório das atividades de prevenção e controle das DSTIAIDS no período de jun 90 a dez 91. São Paulo, 1992. (mimeografado).

23. SÃO PAULO (Cidade). Prefeitura do Município de São Paulo. Programa de Aprimoramento das informações de Mortalidade no Município de São Paulo. São Paulo, 1994. n. 14.

24. SILVA, M. V. da. A justiça é uma conquista da qual somos participantes. Ação anti-aids, n. 14, p. 1-2, 1991.

25. SINGER, P. A crise do "milagre": interpretação crítica da economia brasileira. 8. ed. Rio de Janeiro: Paz e Terra, 1989.

26. SOUZA, H. de. AIDS: o que fazer? Cad. de Saúde Pública, v. 1, n. 2, p. 79-80, jan./mar. 1986.

27. A aids, porque é mortal, criminalizou o sangue. Ação anti-aids, n. 14, p. 3, 1991. 